\title{
A Concept on Order Quantity at Varying Cost in Variable Rate of Production Situation
}

\author{
Dr. Rudresh Pandey, Shradha Goyal, Mayank Kumar Pandey
}

\begin{abstract}
The concept of EOQ is simply to tackle the management issues of inventory in various types of production systems. This is amongst the most popularly used models in the production houses for inventory. A major issue faced by stock manager is to design an effective policy for replacement, resulting outcome as lowest cost of inventory units. Traditional EOQ theory, assumes majorly two factors that is demand and per unit cost. It is assumed that demand remains constant and can be determined at any level. Secondly that per unit production cost does is not dependent on quantity of order for production.

This study is based on a model for stock with multi-item and when per unit cost is dependent on demand and crashing cost of leading time is dependent on lead time. Hence, model has been formulated having constraints of orders and production cost. Unit cost of production is considered fuzzy variable. The jist problem for optimizing the annual total cost has been considered with Karush Kuhn-Tucker conditions method. Mathematical derivations and analysis have been made for one unit, along with testing done from Sensitivity analysis. Illustrations have been taken on random basis.
\end{abstract}

Index Terms: - Inventory, cost, stock, Demand, optimization

\section{INTRODUCTION}

The model concept of EOQ is simply to tackle the management issues of inventory in various types of production systems. This is amongst the most popularly used models in the production houses for inventory. A major issue faced by stock manager is to design an effective policy for replacement, resulting outcome as lowest cost of inventory units. Traditional EOQ theory, assumes majorly two factors that is demand and per unit cost. It is assumed that demand remains constant and can be determined at any level. Secondly that per unit production cost does is not dependent on quantity of order for production.

The company stock contributes as a substantial sharein the total assets of a production house. It is also a crucial concept in the theory of supply chain management. Therefore, because of this importance, an effective inventory management becomes an integral part of the organization's total profit. Usually the problem in EOQ is to resolve and define the optimum value for order quantity and the inventory cost to the minimum.

Generally, factors like cost, demand, quantity, profit are associated with inventory management. Accordingly, the problems of stock management under ambiguous environment can be resolved by accordingly giving fuzzy

Revised Manuscript Received on October 22, 2019.

Dr. Rudresh Pandey ${ }^{1}$, Professor, Department of Management Studies, ABES Engineering College, Ghaziabad, U.P., India.

Dr. Shradha Goyal ${ }^{2}$, Assistant Professor, Jagannath International Management School, New Delhi, India.

Mayank Kumar Pandey ${ }^{3}$, Assistant Professor, Department of Management, JIMS Engineering Management Technical Campus, Greater Noida, U.P., India. value to these parameters. For instance, Ishii \& Konno (1998) studied model based on EOQandfuzzy cost coefficients.Also, Petrovic et aland Park (1987) (1996) discussed the Newsboy modeling theory with fuzzy demand and cost coefficients.Yao \& Chiang (2003) investigated a fuzzy EOQ model with fuzzy demand and rate of defects model. Hang (2004) discussed a with fuzzy holding cost and demand through various solutions.

Traditional models for inventory have deterministic factors as assumptions. However, in reality, there are many variations that occur and cannot be ignored during study. EOQ modeling usually undertakes probabilistic approach to resolve these uncertain situations. By Probabilistic methods, the uncertainty and variations in carrying and holding costs are assumed under definite probability distribution. Although the uncertain factors are not associated with any cost in inventory theory.

In earlier times the Lead time was considered as a fixed parameter in inventory, whereas from past few years it is now taken as a variable which is to be determined by the working inventory model. Although this recent development gives a competitive approach in today's flickering demand in industry and market.

This study is based on a model for stock with multi-item and when per unit cost is dependent on demand and crashing cost of leading time is dependent on lead time. Hence, model has been formulated having constraints of orders and production cost. Per unit cost of production is considered fuzzy variable. The jist problem for optimizing the annual total cost has been considered with Karush Kuhn-Tucker conditions method. Mathematical derivations and analysis have been made for one unit, along with testing done from Sensitivity analysis. Illustration has been taken on random basis.

\section{OBJECTIVES}

For foundation the research workis done to consider different production rate process as stated in the model given by Shukla et. al. [1]. This study explores various factors including cost, demand, production and time with an objective to explore nonlinear functional relationship. Elementaryintention of this study is to explore and develop a mathematical model with nonlinear/ hyperbolic cost function. This research paper also aims to develop and work on giving advanced models with considerations of costfor to optimizing and improvingdifferent total cost in relation to profit, production, and any other costs invarious organizational functions. 


\section{LITERATURE REVIEW}

The model concept of EOQ is simply to tackle the management issues of inventory in various types of production systems. This is amongst the most popularly used models in the production houses for inventory. A major issue faced by stock manager is to design an effective policy for replacement, resulting outcome as lowest cost of inventory units. Traditional EOQ theory, assumes majorly two factors that is demand and per unit cost. It is assumed that demand remains constant and can be determined at any level. Secondly that per unit production cost does is not dependent on quantity of order for production.

The company stock contributes as a substantial sharein the total assets of a production house. It is also a crucial concept in the theory of supply chain management. Therefore, because of this importance, an effective inventory management becomes an integral part of the organization's total profit. Usually the problem in EOQ is to resolve and define the optimum value for order quantity and the inventory cost to the minimum.

Generally, factors like cost, demand, quantity, profit are associated with inventory management. Accordingly, the problems of stock management under ambiguous environment can be resolved by accordingly giving fuzzy value to these parameters. For instance, Ishii \& Konno (1998) studied model based on EOQ and fuzzy cost coefficients.Also, Petrovic et aland Park (1987) (1996) discussed the Newsboy modeling theory with fuzzy demand and cost coefficients.Yao \& Chiang (2003) investigated a fuzzy EOQ model with fuzzy demand and rate of defects. Hang (2004) discussed a model with fuzzy holding cost and demand through various solutions.

Traditional models for inventory have deterministic factors as assumptions. However, in reality, there are many variations that occur and cannot be ignored during study. EOQ modeling usually undertakes probabilistic approach to resolve these uncertain situations. By Probabilistic methods, the uncertainty and variations in carrying and holding costs are assumed under definite probability distribution. Although the uncertain factors are not associated with any cost in inventory theory.

In earlier times the Lead time was considered as a fixed parameter in inventory, whereas from past few years it is now taken as a variable which is to be determined by the working inventory model. Although this recent development gives a competitive approach in today's flickering demand in industry and market.

This study is based on a model for stock with multi-item and when per unit cost is dependent on demand and crashing cost of leading time is dependent on lead time. Hence, model has been formulated having constraints of ordersand cost of production. Per unit cost of production is considered fuzzy variable. The jist problem for optimizing the annual total cost has been considered with Karush Kuhn-Tucker conditions method. Mathematical derivations and analysis have been made for one unit, along with testing done from Sensitivity analysis. Illustration has been taken on random basis.

\section{Problem Design}

\section{A. Assumption and Notations}

Following assumptions and notations are considered in the model, as,

1. Demand can be determined.

2. Zero Lead time. Assuming one time order delivery.

3. Constant and limited production rate $\lambda$, strictly greater than the demand rate $(\mathrm{D})$.

4. Constant cost of set up per unit..

5. Not to allow Backorders.

$\mathrm{D}$ is the per day Demand

$\mathrm{P}$ is the per unit Selling price

$\lambda$ is the production Rate $\backslash$

$\mathrm{C}_{\mathrm{s}}$ is the per unit set up cost

$\mathrm{T}$ is the cycle time of production.

$\mathrm{N}_{\mathrm{i}}$ is the queue size, at $\mathrm{i}^{\text {th }}$ operation

$P_{i}$ is the lot size, at $\mathrm{i}^{\text {th }}$ operation

$\mathrm{Q}$ is the lot numbers

$\mathrm{O}_{\mathrm{i}}$ is the part Value, at $\mathrm{i}^{\text {th }}$ operation

$\mathrm{R}$ is the holding cost/day

$\mathrm{M}_{\mathrm{i}}$ is the cost of set up material.

$\mathrm{L}_{\mathrm{i}}$ is the set up labour rate

$\mathrm{S}_{\mathrm{i}}$ is the integrated Set up time

$\mathrm{k}$ is the summed operations

\section{B. Model Development}

This study is based on a model for stock with multi-item and when per unit cost is dependent on demand and crashing cost of leading time is dependent on lead time. Hence, model has been formulated having constraints of orders and cost of production. Per unit cost of production is considered fuzzy variable. The jist problem for optimizing the annual total cost has been considered with Karush Kuhn-Tucker conditions method. Mathematical derivations and analysis have been made for one unit, along with testing done from Sensitivity analysis. Illustration has been taken on random basis.

\section{Methodology}

Objective is to reduce the total expected annual cost to minimum, total expected annual costis the sum of order of production, lead time crashing costs and inventory carrying cost; according to EOQ and its basic assumptions following is the cost details -

$\operatorname{TC}\left(D_{i}, Q_{i}, L_{i}\right)=\sum_{i=1}^{n}\left\{p_{i} D_{i}+\frac{S_{i} D_{i}}{Q_{i}}+\left[\frac{Q_{i}}{2}+K \sigma \sqrt{L_{i}}\right] H_{i}+\frac{D_{i}}{Q_{i}} R\left(L_{i}\right)\right\}$

Substituting pi and $\mathrm{R}(\mathrm{Li})$ in Equation (1) gives

$\operatorname{TC}\left(D_{i}, Q_{i}, L_{i}\right)=\sum_{i=1}^{n}\left[A D_{i}^{1-\beta}+\frac{S_{i} D_{i}}{Q_{i}}+\left[\frac{Q_{i}}{2}+K \sigma \sqrt{L_{i}}\right] H_{i}+\frac{D_{i}}{Q_{i}} \alpha L_{i}^{-b_{i}}\right]$ 
Using Karush Kuhn-Tucker conditions method for a single item, the problem can be formulated as:

$\operatorname{MinTc}(D, Q, L)=A D^{1-\beta}+\frac{S D}{Q}+\left[\frac{Q}{2}+K \sigma \sqrt{L}\right] H+\frac{D}{Q} \alpha L^{-b}$

subject to the inequality constraints

$$
\begin{aligned}
& A D^{-\beta} Q \leq B \\
& \frac{\boldsymbol{D}}{\boldsymbol{Q}} \leq \boldsymbol{t}
\end{aligned}
$$

This is a minimization problem for a single item without shortage under two constraints. It can be solved by using Karush Kuhn-Tucker approach.

By using Karush Kuhn-Tucker method the above function can be restated as

$G=A D^{1-\beta}+\frac{S D}{Q}+\left[\frac{Q}{2}+K \sigma \sqrt{L}\right] H+\frac{D}{Q} \alpha L^{-b}-\lambda_{1}\left(B-A D^{-\beta} Q-s_{1}^{2}\right)-\lambda_{2}\left(t-D Q^{-1}-s_{2}^{2}\right)$ (1.6)

Differentiating (6) partially with respect to D, Q and L we get the following equations

$$
\begin{gathered}
\frac{\partial G}{\partial D}=(1-\beta) A D^{-\beta}+S Q^{-1}+\alpha Q^{-1} L^{-b}-\beta \lambda_{1} A D^{-\beta-1} Q+\lambda_{2} Q^{-1} \\
\frac{\partial G}{\partial D}=-S D Q^{-2}+0.5 H-\alpha D Q^{-2} L^{-b}+\lambda_{1} A D^{-\beta}-\lambda_{2} D Q^{-2} \\
\frac{\partial G}{\partial D}=0.5 K \sigma L^{-0.5} H-\alpha b D Q^{-1} L^{-b-1}
\end{gathered}
$$

The necessary conditions for KKT conditions are

$$
\frac{\partial G}{\partial D}=0 \Rightarrow(1-\beta) A D^{-\beta}+S Q^{-1}+\alpha Q^{-1} L^{-b}-\beta \lambda_{1} A D^{-\beta-1} Q+\lambda_{2} Q^{-1}=0
$$

$$
\frac{\partial G}{\partial D}=0 \Rightarrow-S D Q^{-2}+0.5 H-\alpha D Q^{-2} L^{-b}+\lambda_{1} A D^{-\beta}-\lambda_{2} D Q^{-2}=0
$$

$$
\frac{\partial G}{\partial D}=0 \Rightarrow 0.5 K \sigma L^{-0.5} H-\alpha b D Q^{-1} L^{-b-1}=0
$$

Solving the above set to Equations (1.7), (1.8) and (1.9) gives the optimal solution of the decision variables $\mathrm{D}, \mathrm{Q}$ and L.

For solving these equations the Newton Raphson method has been applied to obtain the solution of the transcendental equation.

\section{Policy: For Variable P and D}

For solving these equations the Newton Raphson method has been applied to obtain the solution of the transcendental equation.

$$
\frac{D}{Q} \leq t
$$

For, $\mathrm{P}, \mathrm{D}>0 \quad \Rightarrow \mathrm{D}=\mathrm{Pf}$

(1.11)

The demand function (1.11) is minimization problem for a single item without shortage under two constraints.

Hence (1.10) and (1.11) shows demand function for fixed mark - up of prices,

$\mathrm{D}=\mathrm{Qf}$

\section{Case 1}

Here let,
a) Variable D.
b) Fixed $P$
c) Cost with Quantity Discounts

Then profit function $\mathrm{Z}(\mathrm{Q})$ can be calculated from equation (1.9) and equation (1.12)

$\mathrm{Z}(\mathrm{Q})=(\theta-1)(C Q) \mathrm{fCQ}-\frac{\underline{c}_{0}}{\mathrm{\alpha}}-\frac{k}{\mathrm{Q} \lambda \theta}(13)$

Let us consider, $\mathrm{D}=K P^{-\eta}(14)$

Where $\eta$ is the elasticity of demand $\epsilon(0, \infty)$

Therefore, (1.13) and (1.14) gives,

$\mathrm{Z}(\mathrm{Q})=$

$K \theta^{-\eta}(\theta-1)(C Q)^{\eta+1}-\left[\sum_{i=1}^{k}\left(N_{i}+P_{i}\right) Q O_{i} R-\right.$

$\frac{1}{2} \sum_{i=1}^{k}\left(N_{i}+P_{i}\right) Q O_{i} R K \theta^{-\eta}(C Q)^{-\eta}+$

$\left.\left.\sum_{i=1}^{k} \frac{\left(L_{i} S_{i}+M_{i}\right) M(C Q)^{-T}}{Q^{\top}}\right)\right]$

)

Consider $\mathrm{C}(\mathrm{Q})=\mathrm{C}_{0}-{ }_{\mathrm{Q}} \mathrm{Q}$, then (13) becomes,

$\mathrm{Z}(\mathrm{Q})=\mathrm{K}($

$\theta-1) \theta^{-\eta} C_{0}-a Q^{-\eta+1}-\sum_{i=1}^{k}\left(N_{i}+P_{i}\right) Q O_{i} R+$

$\frac{K}{\lambda \theta^{\eta}} \sum_{i=1}^{k}\left(N_{i}+P_{i}\right) Q O_{i} R C_{0}-\alpha Q^{-\eta}-\frac{K}{Q \theta^{\eta}} \sum_{i=1}^{k}\left(L_{i} S_{i}+\right.$ $\left.M_{\mathrm{i}}\right)\left(C_{\mathrm{n}}-\alpha Q\right)^{-\eta}$

Differentiating equation (13), Finding $\frac{\partial Z}{\partial Q}=0$, gives

$\mathrm{K}=$

$$
\begin{gathered}
\frac{\partial G}{\partial D}=(1-\beta) A D^{-\beta}+S Q^{-1}+\alpha Q^{-1} L^{-b}-\beta \lambda_{1} A D^{-\beta-1} Q+\lambda_{2} Q^{-1} \\
\frac{\partial G}{\partial D}=-S D Q^{-2}+0.5 H-\alpha D Q^{-2} L^{-b}+\lambda_{1} A D^{-\beta}-\lambda_{2} D Q^{-2} \\
\frac{\partial G}{\partial D}=0.5 K \sigma L^{-0.5} H-\alpha b D Q^{-1} L^{-b-1}
\end{gathered}
$$

We get a rectangular Hyperbola in Demand Curve for $\eta=1$ for each point on the curve; therefore (1.17) becomes,

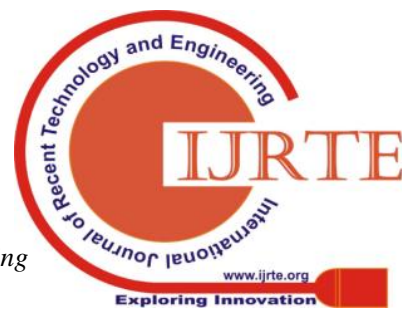


$\frac{\partial G}{\partial D}=0 \Rightarrow(1-\beta) A D^{-\beta}+S Q^{-1}+\alpha Q^{-1} L^{-b}-\beta \lambda_{1} A D^{-\beta-1} Q+\lambda_{2} Q^{-1}=0$

As $\lambda \rightarrow \infty$, equation (1.18) reduces to,

$\frac{\partial G}{\partial D}=0 \Rightarrow-S D Q^{-2}+0.5 H-\alpha D Q^{-2} L^{-b}+\lambda_{1} A D^{-\beta}-\lambda_{2} D Q^{-2}=0$

(1.19) gives and considers

$\mathrm{H}_{2}=\frac{2 C_{10}}{\ltimes}$

$\mathrm{H}_{1}=\frac{c_{\mathrm{I}}^{2}}{\kappa^{2}}$

$\mathrm{H}_{4}=\frac{2 k \sum_{i=1}^{k}\left(L_{i} \Phi_{i}+M_{i}\right)}{\operatorname{\alpha in} \sum_{i=1}^{k}\left(M_{i}+P_{i}\right) Q_{i} R}$

$\mathrm{H}_{4}=\frac{c_{0} k \sum_{i=1}^{k}\left(L_{i} S_{i}+M_{i}\right)}{\mathbb{E}^{2} \theta \sum_{i=1}^{k}\left(N_{i}+P_{i}\right) \sigma_{i} R}$

Considering rate of production to be finite, equation (1.14) becomes,

$Q^{4}-H_{5} Q^{2}+H_{6} Q^{2}+H_{7} Q-H_{8}=0$

Where

$$
\begin{aligned}
& \mathrm{H}_{5}=\frac{2 C_{0}}{a} \\
& \mathrm{H}_{6}=\frac{C_{0}}{a}-\frac{k}{a \lambda \theta}
\end{aligned}
$$

$\mathrm{H}_{7}=\frac{2 k \sum_{i=1}^{k}\left(L_{i} \xi_{i}+M_{i}\right)}{\sigma \theta \sum_{i=1}^{k}\left(N_{i}+P_{i}\right) O_{i} R}$

$\mathrm{H}_{8}=\frac{C_{\mathrm{D}} k \sum_{i=1}^{k}\left(L_{i} S_{i}+M_{i}\right)}{\kappa^{2} \theta \sum_{i=1}^{k}\left(N_{i}+P_{i}\right) O_{i} R}$

Using Karush Kuhn-Tucker conditions method for a single item, the problem can be formulated as:

1. Now let $\eta=1$ be taken when considering constant cost,

$Q_{c}^{*}=\sqrt{\frac{K \sum_{i=1}^{k}\left(L_{i} S_{i}+M_{i}\right)}{C_{0} \theta \sum_{i=1}^{k}\left(N_{i}+P_{i}\right) O_{i} R\left(1+\frac{k}{\lambda \theta C_{0}}\right)}}$

$\frac{\partial(\mathrm{TIC})}{\partial \mathrm{T}^{2}}=-\frac{2}{\mathrm{~T}^{3}}\left[\mathrm{k}+\frac{\mathrm{s} \alpha\left(\mathrm{T}-\mathrm{T}_{1}\right)^{2}}{2}+\frac{\alpha\left(\mathrm{h}+\mathrm{c}^{*} \theta\right)}{\theta+\beta}\left\{\frac{\mathrm{e}^{(\theta+\beta) \mathrm{T}_{1}}-1}{\theta+\beta}-\mathrm{T}_{1}\right\}\right]+\frac{\mathrm{s} \alpha}{\mathrm{T}^{2}}\left(2 \mathrm{~T}_{1}-\mathrm{T}\right)>0$

2. Let $\lambda \rightarrow \infty$, then (1.20) reduces to,
For variable cost,

$$
C Q=b+\frac{d}{Q}\left(Q_{0} \leq Q<\infty\right)
$$

The profit function becomes,

$Z Q=K(\theta-1) Q^{-\eta}\left(b+\frac{d}{\theta}\right)^{-\eta+1}$

$\frac{\partial(\mathrm{TIC})}{\partial \mathrm{T}}=-\frac{1}{\mathrm{~T}^{2}}\left[\mathrm{k}+\frac{\mathrm{s} \alpha\left(\mathrm{T}-\mathrm{T}_{1}\right)^{2}}{2}+\frac{\alpha\left(\mathrm{h}+\mathrm{c}^{*} \theta\right)}{\theta+\beta}\left\{\frac{\mathrm{e}^{(\theta+\beta) \mathrm{T}_{\mathrm{I}}}-1}{\theta+\beta}-\mathrm{T}_{1}\right\}\right]+\frac{\mathrm{s} \alpha\left(\mathrm{T}-\mathrm{T}_{1}\right)}{\mathrm{T}}$

$\Rightarrow \quad \frac{\partial Z}{\partial Q}=0$ gives,

$\frac{1}{Q^{2}} k(\theta-1) \theta^{-\eta}(\eta-1)+\frac{d}{Q}^{-\eta}$

$+\sum_{i=1}^{k}\left(N_{i}+P_{i} O_{i} R\right)+\frac{k}{\lambda \theta^{\eta}}$

$\sum_{i=1}^{k}\left(N_{i}+P_{i} O_{i} R\right)+\left(b+\frac{d}{Q}\right)^{-\eta-1}\left(b+\frac{d}{Q}+\frac{d \eta}{Q}\right)$

$+\frac{K}{\theta^{\eta} Q^{2}} \sum_{i=1}^{k}\left(L_{i} S_{i}+M_{i}\right)\left(b+\frac{d}{Q}\right)^{-\eta-1}$

$\left(b+\frac{d}{Q}-\frac{d \eta}{Q}\right)=0$

For special case $\eta=1$ eqn. (1.23) becomes,

$-\sum_{i=1}^{k} N_{i}+P_{i} O_{i} R+\frac{K}{\lambda \theta} \quad \sum_{i=1}^{k} N_{i}+P_{i} O_{i} R+\left(b+\frac{d}{Q}\right)^{-2}$

$\left(b+\frac{2 d}{Q}\right)+\frac{k b}{\theta Q^{2}}$

$\sum_{i=1}^{k}\left(L_{i} S_{i}+M_{i}\right)\left(b+\frac{d}{Q}\right)^{-2}=0$

Simplifying further,

$\sum_{i=1}^{k} N_{i}+P_{i} O_{i} R+\left(1-\frac{k}{\lambda \theta}\right)\left(b+\frac{d}{Q}\right)^{-2}\left(b+\frac{2 d}{Q}\right)+\frac{k b}{Q \theta^{2}}$

\section{Case of Hyperbolic Function}


$\sum_{i=1}^{k}\left(L_{i} S_{i}+M_{i}\right)\left(b+\frac{d}{Q}\right)^{-2}$

$\Rightarrow \frac{\partial^{2}(\mathrm{TIC})}{\partial \mathrm{T}^{2}}>0$

Substituting (1.24) in (1.22), gives $Q^{*}$ relative to $Z^{*}$

\section{Cost as Constant Function}

In $C Q=b+\frac{d}{Q}$, assume $\mathrm{d}=$ constant; $\left(Q_{0} \leq 1<\infty\right)$

Hence for $\eta=1 \&$ constant cost,

$Q_{c}^{*}=\left[\frac{K b \sum_{i=1}^{k} L_{i} S_{i}+M_{l}}{\theta \sum_{i=1}^{k} N_{i}+P_{i} Q_{l} R\left(b^{2}-\frac{K b}{\lambda \theta}\right)}\right]^{1 / 2}$

And

$\frac{\partial^{2}(\mathrm{TIC})}{\partial \mathrm{T} \partial \mathrm{T}_{1}}=\frac{\alpha}{\mathrm{T}^{2}}\left\{\mathrm{sT}_{1}+\frac{\left(\mathrm{h}+\mathrm{c}^{*} \theta\right)}{\theta+\beta}\left(\mathrm{e}^{(\theta+\beta) \mathrm{T}_{1}}-1\right)\right\}<0$

$\mathrm{TIC}=\frac{1}{\mathrm{~T}}[\mathrm{OC}+\mathrm{SC}+\mathrm{HC}+\mathrm{CD}]$

$+\frac{K}{\lambda \theta b} \sum_{i=1}^{k}\left(N_{i}+P_{i} Q_{c}^{*} O_{i} R\right)-\frac{K}{\theta b} \frac{\sum_{i=1}^{k}\left(L_{i} S_{i}+M_{i}\right)}{Q_{c}^{*}}$

If $\lambda \rightarrow \infty$, then (1.24) \& (1.25) becomes,

$2 \mathrm{k}-\mathrm{s} \alpha\left(\mathrm{T}^{2}-\mathrm{T}_{1}^{2}\right)+\frac{2 \alpha\left(\mathrm{h}+\mathrm{c}^{*} \theta\right)}{\theta+\beta}\left(\frac{\mathrm{e}^{(\theta+\beta) \mathrm{T}_{1}}-1}{\theta+\beta}-\mathrm{T}_{1}\right)=0$

(1.26) And

$\left(\mathrm{h}+\mathrm{c}^{*} \theta\right)(\theta+\beta) \mathrm{T}_{1}^{2}+2\left(\mathrm{~h}+\mathrm{s}+\mathrm{c}^{*} \theta\right) \mathrm{T}_{1}-2 \mathrm{sT}=0$

$(1.27)$

\section{PROBLEM}

Suppose that the following information is given:

$\mathrm{D}=54$ Units, $=60$ Units, $\mathrm{P}=.3 \mathrm{Rs}$. / Unit, $\mathrm{R}=0.01, \mathrm{~K}=5$, the following results can be calculated.

For Variable $\mathrm{P}$ and D Cost function is linearly taken as,
Table 1 Results for Linear Costs Function

\begin{tabular}{|c|c|c|c|c|}
\hline Case & $\theta$ & $\boldsymbol{C}_{\mathbf{0}}$ & $\boldsymbol{Q}^{*}$ & $\boldsymbol{Z}^{*}$ \\
\hline \multirow{4}{*}{ Case (a) } & 2 & 5 & 19.79 & 18.42 \\
\cline { 2 - 5 } & 3 & 5 & 16.14 & 28.01 \\
\cline { 2 - 5 } & 4 & 5 & 13.97 & 32.88 \\
\cline { 2 - 5 } & 5 & 5 & 12.49 & 35.87 \\
\hline \multirow{4}{*}{ Case (b) } & 2 & 4 & 22.15 & 17.72 \\
\cline { 2 - 5 } & 2 & 3 & 25.63 & 16.62 \\
\cline { 2 - 5 } & 2 & 2 & 31.5 & 14.76 \\
\hline \multirow{5}{*}{ Case (c) } & 3 & 4 & 45.03 & 10.68 \\
\cline { 2 - 5 } & 4 & 3 & 18.06 & 27.38 \\
\hline \multirow{3}{*}{ Case (d) } & 5 & 2 & 19.79 & 31.55 \\
\cline { 2 - 5 } & 6 & 2 & 18.06 & 35.48 \\
\cline { 2 - 5 } & 4 & 3 & 16.14 & 34.67 \\
\hline & 4 & 4 & 15.62 & 32.34 \\
\hline
\end{tabular}

\section{Hyperbolic Cost Function for Variable P and D}

Table 1b Results for Hyperbolic Costs Function

\begin{tabular}{|c|c|c|c|c|}
\hline Case & $\theta$ & $\mathbf{b}$ & $\boldsymbol{Q}^{*}$ & $\boldsymbol{Z}_{\boldsymbol{c}}{ }^{*}$ \\
\hline \multirow{4}{*}{ Case (a) } & 2 & 10 & 13.97 & 20.38 \\
\cline { 2 - 5 } & 3 & 10 & 11.4 & 29.56 \\
\cline { 2 - 5 } & 4 & 10 & 9.86 & 34.22 \\
\cline { 2 - 5 } & 5 & 10 & 8.82 & 37.08 \\
\hline \multirow{5}{*}{ Case (b) } & 2 & 8 & 15.62 & 19.84 \\
\cline { 2 - 5 } & 2 & 6 & 18.06 & 19.05 \\
\cline { 2 - 5 } & 2 & 4 & 22.15 & 17.72 \\
\hline \multirow{5}{*}{ Case (c) } & 3 & 11 & 10.86 & 29.74 \\
\cline { 2 - 5 } & 5 & 9 & 9.3 & 36.92 \\
\hline \multirow{3}{*}{ Case (d) } & 7 & 7 & 8.91 & 39.9 \\
\cline { 2 - 5 } & 11 & 3 & 10.86 & 41.86 \\
\hline & 7 & 5 & 9.3 & 41.36 \\
\hline & & 7 & 8.91 & 39.9 \\
\hline
\end{tabular}

\section{RESEARCH LIMITATION}

The basic limitation of this research is that it has been devloped with different variables and it needs more application data in real and working conditions in various SMEs (small and medium industries).

It is observed that SMEs do not have EOQ models which are optamised in contrast to large scale industries which use and have access to various models for inventory. Real time data will make this model more robust and useful. 


\section{CONCLUSION}

With the help of sensitivity analysis, the outcome of equation (1.15) for cost in hyperbolic function is compared to the output of equation (1.12) for cost in linear functions.This is shown in table (1a) and table (1b) respectively, fourgraphs are drawn in four different situations. The graphs can also be used toshow that hyperbolic cost function will give an optimized value of Profit and Quantity both it is also compared to output from Cost Function which is linear.

\section{FUTURE SCOPE}

This paper has done basic work to develop an optimized EOQ model for small and medium enterprises (SMEs). SMEs do not have access to EOQ models. This paper gives an opportunity to develop an EOQ model which is optimized to the requirments of different industries. Further studies can be done to implement ths model in practical conditions.

\section{REFERENCES}

1. Soni, H. N., \& Joshi, M., "A fuzzy framework for coordinating pricing and inventory policies for deteriorating items under retailer partial trade credit financing", Computers \& Industrial Engineering, Vol. 66 Issue 4, 2013, pp. 865-878.

2. Alfares, H. K., \& Ghaithan, A. M., "Inventory and pricing model with price-dependent demand, time-varying holding cost, and quantity discounts", Computers \& Industrial Engineering, Vol. 94, 2016, pp. 170-177.

3. Shah, N. H., Patel, A. R., \& Lou, K. R., "Optimal ordering and pricing policy for price sensitive stock-dependent demand under progressive payment scheme", International Journal of Industrial Engineering Computations, Vol. 2 No. 3, 2011, pp. 523-532.

4. Rumyantsev, S. and Netessine, S., "What can be learned from classical inventory models? A cross-industry exploratory investigation", Manufacturing \& Service Operations Management, Vol. 9 No. 4, 2007, pp. 409-429.

5. Chung, K. J., Cárdenas-Barrón, L. E., \&Ting, P. S., “An inventory model with non-instantaneous receipt and exponentially deteriorating items for an integrated three layer supply chain system under two levels of trade credit", International Journal of Production Economics, Vol. 155, 2014, pp. 310-317.

6. Shah, N.H., Soni, H.N., Patel, K.A., "Optimizing inventory and marketing policy for non-instantaneous deteriorating items with generalized type deterioration and holding cost rates", Omega, Vol. 41, Issue 2, April 2013, pp. 421-430

7. Hariga, M.A., "Effects of inflation and time-value of money on an inventory model with time-dependent demand rate and shortages", European Journal of Operational Research, Vol. 81, Issue 3, 16 March 1995, pp. 512-520.

8. Singh, V.K., Jain, R., Kankanhalli, M.S., "Motivating contributors in social media networks", WSM '09 Proceedings of the first SIGMM workshop on Social media, ISBN: 978-1-60558-759-2, October 2009, Pg. 11-18.

9. Yang, H.L., Teng, J.T., Chern, M.S., "An inventory model under inflation for deteriorating items with stock dependent consumption rate and partial backlogging shortages", International Journal of production Economics, Vol. 123, Issue 1, January 2010, pp. 8 - 19.

10. Chen, C.K., Chang, H.C., Ouyang, L.Y., "Lead time and ordering cost reductions in continuous review inventory systems with partial backorders", Journal of the Operations Research Society, Vol. 50, Issue 12, December 1999, pp. 1272 - 1279.

11. Guria, A., Das, B., Mondal, S., Maiti, M., "Inventory policy for an item with inflation induced purchasing price, selling price and demand with immediate part payment", Applied Mathematical Modelling, Vol. 37, Issue 1-2, January 2013, pp. $240-257$.

12. Yadav, D., Singh, S.R., Kumari, R., "Retailer's optimal policy under inflation in fuzzy environment with trade credit", International Journal of Systems Science, Vol. 46, Issue 4, September 2015, pp. 68 82.

13. Sharma, S., Singh, S.R., "An Inventory Model for Decaying Items, considering Multi Variate Consumption Rate with Partial Backlogging”, Indian Journal of Science and Technology, Vol. 6, Issue 7, July 2013, pp. $43-54$.
14. Sarkar, B., Gupta, H., Chaudhari, K., Goyal, S.K., "An integrated inventory model with variable lead time, defective units and delays in payments", Applied Mathematical and Computations, Vol. 237, Issue 3, June 2014, pp. $650-658$.

15. Sarkar, B., "An inventory model with reliability in an imperfect production process", Applied Mathematics and Computation, Vol. 218, Issue 9, January 2012, pp. 4881-4891.

16. Sarkar, B., Sarkar, S., "Am improved inventory model with partial backlogging, time varying deterioration and stock dependent demand", Economic Modelling, Vol. 30, January 2013, pp. 924 - 932.

17. Wu, G., Bekaert, G., "Asymmetric Volatility and Risk in Equity Markets", The Review of Financial Studies, Vol. 13, Issue 1, 1 January 2000, pp. 1-42.

\section{AUTHORS PROFILE}

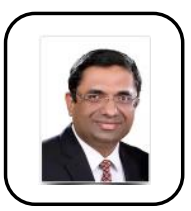

Dr. Rudresh Pandey has over 16 years of experience in corporate, management education and entrepreneurship. He has diverse experience in the areas of general management, marketing, entrepreneurship, B2B marketing, research and advertising. Dr. Pandey's corporate work experience has been in the field of education rating, women entrepreneurship and education technologies including MNCs and Top Indian companies like - Reed Business Information, India Today (Living Media Group) in Mumbai. ONICRA Credit Rating Agency of India Ltd and Impact Marketing Services Pvt Ltd in Delhi/NCR.

Entrepreneurship has been his area of special interest and his Phd topic had been Women Entrepreneurship. He had been instrumental in setting up Entrepreneurship cell in various colleges where he served as a Professor.

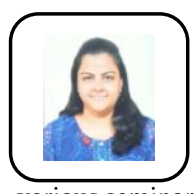

Dr. Shradha Goyal has over 10 years of rich experience in Academics. Dr. Goyal completed her doctorate from Jagannath University and is Graduate and Post Graduate in Mathematics honors from Panjab University Campus, Chandigarh She has participated and presented Papers in various seminar and conferences of National \& International repute. She has published several research papers in refereed and reputed journals indexed in UGC and SCOPUS. She has also authored a book titled "Basics of Linear Programming". Dr. Shradha Goyal is associated with Jagannath International Management School, Kalkaji, New Delhi. She is committed towards her responsibilities and gives a mentorship support in Progress of students.

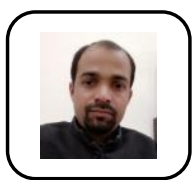

Mr. Mayank Kr. Pandey has over 12 years of rich experience in industry and management education. $\mathrm{Mr}$. Pandey completed his B Com. (2002) from Deen Dayal Upadhyay Gorakhpur University, Gorakhpur, and secured his MBA (2007) from Uttar Pradesh Technical University, Lucknow. He is pursuing Ph.D., he has participated and presented various seminar and conferences of National \& International repute. He has published several research papers in reputed journals, he has also authored a book for management students and with all his eccentric efforts corrected the abysmal of his students. Acclaiming concentric \& specific managerial skills Mr. Mayank Kumar Pandey is an adapt in handling experiences with his commitment, Mr. Pandey is acclimatized to support students and society's growth. 